09,12

\title{
Особенности дифракции света в упорядоченном монослое сфер
}

\author{
(C) С.Г. Романов \\ Физико-технический институт им. А.Ф. Иофрфе РАН, \\ Санкт-Петербург, Россия \\ Institute of Particle Technology, University of Erlangen-Nuremberg, \\ Erlangen, Germany \\ E-mail: sergeiromano1@mail.ru
}

(Поступила в Редакцию 17 октября 2016 г.)

\begin{abstract}
Исследованы структура и оптические дифракционные свойства монослоев монодисперсных сфер, кристаллизованных на прозрачных диэлектрических подложках. Рассмотрены два типа дифракционных явлений: поверхностная дифракция света на решетке сфер и волноводные резонансы в плоскости монослоя. Для экспериментального исследования этих явлений измерены оптические спектры ретроотражения и пропускания в зависимости от угла падения света и азимутальной ориентации плоскости падения. Найдено количественное совпадение между структурой монослоя, определенной методами сканирующей электронной микроскопии и дифракции света. Сделан вывод о применимости одномерной дифракции Фраунгофера для описания поверхностной дифракции в гексагональной решетке сфер. В случае наклонного падения света найдена анизотропия спектров дифракции и пропускания в зависимости от ориентации плоскости падения света относительно решетки сфер и линейной поляризации падающего света. Волноводные резонансы плоского двумерного фотонного кристалла аппроксимированы в рамках модели дифракции света в „пустой“ гексагональной решетке. Наилучшая аппроксимация дисперсии волноводного резонанса достигнута при использовании зависящего от длины волны эффективного показателя преломления. Продемонстрировано подавление поверхностной дифракции волноводными резонансами фотонного кристалла. Порядки поверхностной дифракции идентифицированы как дифракция в особых точках зон Бриллюэна плоского двумерного фотонного кристалла.
\end{abstract}

Работа выполнена при частичной финансовой поддержке DFG Cluster of Excellence „Engineering Advanced Materials“ (Germany).

DOI: 10.21883/FTT.2017.07.44597.384

\section{1. Введение}

Упорядоченные монослои диэлектрических монодисперсных сфер (рис. 1) вызывают неизменный интерес исследователей уже около 30 лет [1]. Если на ранних этапах изучения монослоев сфер были развиты идеи формирования их фотонной зонной структуры [2,3], то в настоящее время они привлекают внимание, например, в качестве перспективного структурного элемента для управления потоком света в светоизлучающих и фотоэлектрических приборах $[4,5]$.

В последние годы получили развитие производные от морфологии монослоя, такие как плоское двумерное фотонное стекло с регулируемой степенью беспорядка [6], структуры с неплотной упаковкой [7] и встроенной иерархией $[8,9]$. Эти конфигурации уникальны, так как в отличие от трехмерных ансамблей сфер подложка выполняет роль механического стабилизатора структуры монослоев, снимая требование плотной упаковки.

Помимо этого было продемонстрировано, что монослои сфер технологически несложно совмещать с другими структурными элементами. Наибольшее распространение получили комбинации монослоев с металлами, проявляющими плазмонные свойства [10]. Такие структуры, как монослои сфер, выращенные на плоских металлических подложках [11-13], или покрытые пленками металлов, конформно повторяющими топологию поверхности монослоя $[14,15]$, или инвертированные металлом [16,17], привлекают внимание исследователей очень широким диапазоном изменения оптических свойств [10]. Эти архитектуры демонстрируют свойства фотонных, плазмонных и гибридных плазмоннофотонных кристаллов, причем в зависимости от модификации в свойствах металло-диэлектрических монослоев

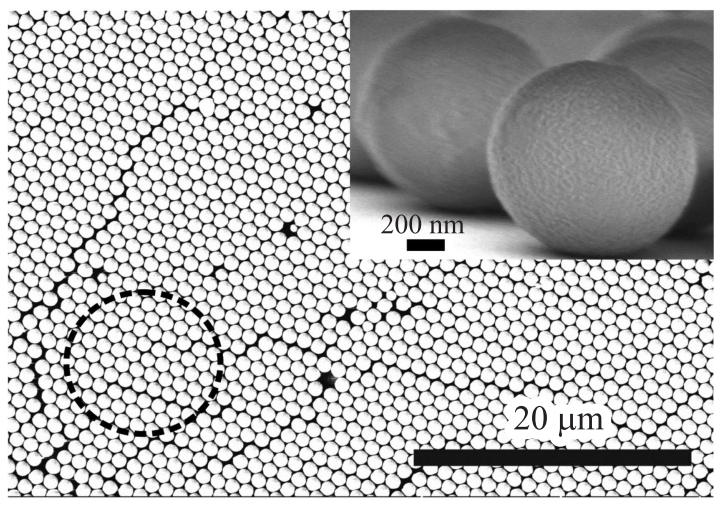

Рис. 1. SEM-снимок монослоя сфер, вид сверху. На вставке вид на монослой сбоку. Штриховая окружность дает представление об области когерентной поверхностной дифракции при освещении решетки белым светом. 
сфер могут доминировать как локализованные, так и распространяющиеся плазмон-поляритоны.

Подложки, стабилизирующие монослои, в свою очередь оказывают влияние на оптические свойства монослоев. Недостаток конструкции заключается в том, что показатель преломления подложки, как правило, превосходит эффективный показатель преломления монослоя сфер. Фактически, локализация электромагнитного поля в монослое, позволяющая рассматривать его как плоский волновод, поддерживается тем, что касание подложки и сферы происходит в одной точке [13]. Для борьбы с утечкой электромагнитной энергии из монослоя в подложку либо приготавливают монослои сфер в виде мембран [18], либо изолируют подложку от монослоя металлическим зеркалом [13].

Поскольку в современных архитектурах монослои монодисперсных диэлектрических сфер являются или составной частью структуры, или матрицей для получения производных структур, оптические свойства монослоев используются в качестве отправной точки для объяснения дифракции света в соответствующих комплексных объектах. Именно на этом этапе исследователь сталкивается с недостаточностью имеющегося базиса. Такие вопросы, как спектральное положение резонансов в зависимости от периода решетки, пространственная и поляризационная анизотропия, решаются численным моделированием, при этом вопросы физической интерпретации остаются за скобками. С целью восполнения имеющихся пробелов в настоящей работе модели обратимся к детальному экспериментальному исследованию дифракции света на упорядоченном монослое сфер и свяжем структурные и оптические свойства монослоя.

Свет, падающий на упорядоченный монослой сфер, испытывает рассеяние. Интерференция однократно рассеянных на решетке электромагнитных волн приводит к возникновению дифракционной картины в зоне дальнего поля аналогично действию отражающих и пропускающих дифракционных решеток (рис. 2,a). Другая часть падающего света захватывается в плоскости монослоя и испытывает многократное рассеяние, формируя набор разрешенных для распространения собственных мод кристалла (рис. 2,b). Этот набор составляет фотонную энергетическую структуру монослоя, которая определяет функционирование монослоя как плоского двумерного фотонного кристалла. Моды, доступные для связи с излучением в пределах светового конуса, являются волноводными резонансами [19]. Волноводные резонансы фотонного кристалла отбирают энергию из проходящего пучка, перенаправляя и рассеивая свою долю падающего потока света. Строго говоря, эти моды существуют только в пределах решетки кристалла, и мы их наблюдаем как максимумы или минимумы в измеряемых спектрах в соответствии с фазовой задержкой переизлученного кристаллом света. Процессы возбуждения мод фотонного кристалла и излучения в пространство вне кристалла актуальны, например, для фотонно-кристаллических светодиодов [20] как средство

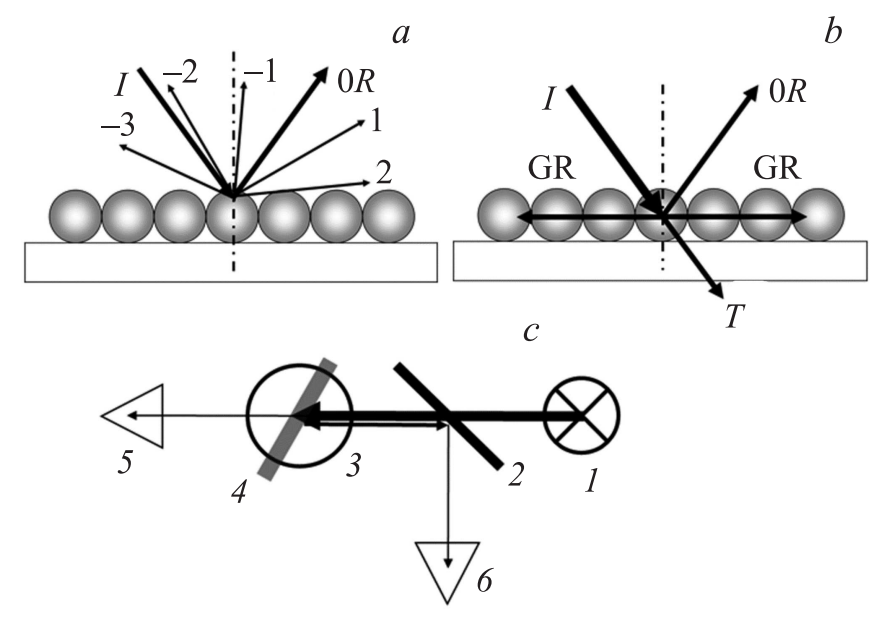

Рис. 2. a) Схема поверхностной дифракции на фотонном кристалле, при которой падающий свет $(I)$ разделяется на отраженный свет в нулевом порядке дифракции $(0 R)$ и ряд более высоких порядков дифракции $(-3,-2,-1,1,2) . b)$ Схема дифракции в фотонном кристалле, в котором падающий свет $(I)$ разделяется на отраженный в нулевом порядке дифракции свет $(0 R)$, прошедший свет $(T)$ и волноводные резонансы в плоскости кристалла (GR). c) Схема эксперимента: свет от лампы (1) через полупрозрачную пластинку (2) падает на закрепленный на вращающемся основании (3) образец (4). Прошедший свет регистрируется спектрометром (5), а ретроотраженный свет - спектрометром (6).

повышения их энергоэффективности и формирования диаграммы направленности излучения.

Измерения в нулевом порядке дифракции спектра прошедшего фотонный кристалл света позволяют детектировать волноводные резонансы. С целью селективного возбуждения различных собственных резонансов изменяют, как правило, угол падения света, его поляризацию и ориентацию плоскости падения света относительно решетки кристалла $[21,22]$. При этом порядки дифракции выше нулевого остаются неучтенными. Для детектирования более высоких чем нулевой, дифракционных порядков проводят измерения, отступая от направления падения луча или от плоскости зеркального отражения [23,24]. В частности, с этой целью мы предложили использовать ретроотражение (рис. 2,c) [25].

Поскольку оба типа дифракционных явлений связаны с одной и той же решеткой, знание, например, поверхностной дифракции, дающей информацию о периоде решетки кристалла, позволяет оценить размеры зоны Бриллюэна, которая определяет фотонную энергетическую структуру. Существенным доводом в пользу совместного измерения спектров пропускания и ретроотражения является тот факт, что параметры падающей волны, возбуждающей поверхностную дифракцию и волноводные резонансы, одинаковы для обоих методов. Это обстоятельство обусловливает также взаимосвязь двух измеряемых проявлений дифракции света.

В настоящей работе мы описали структуру монослоя сфер на основе данных сканирующей электронной мик- 


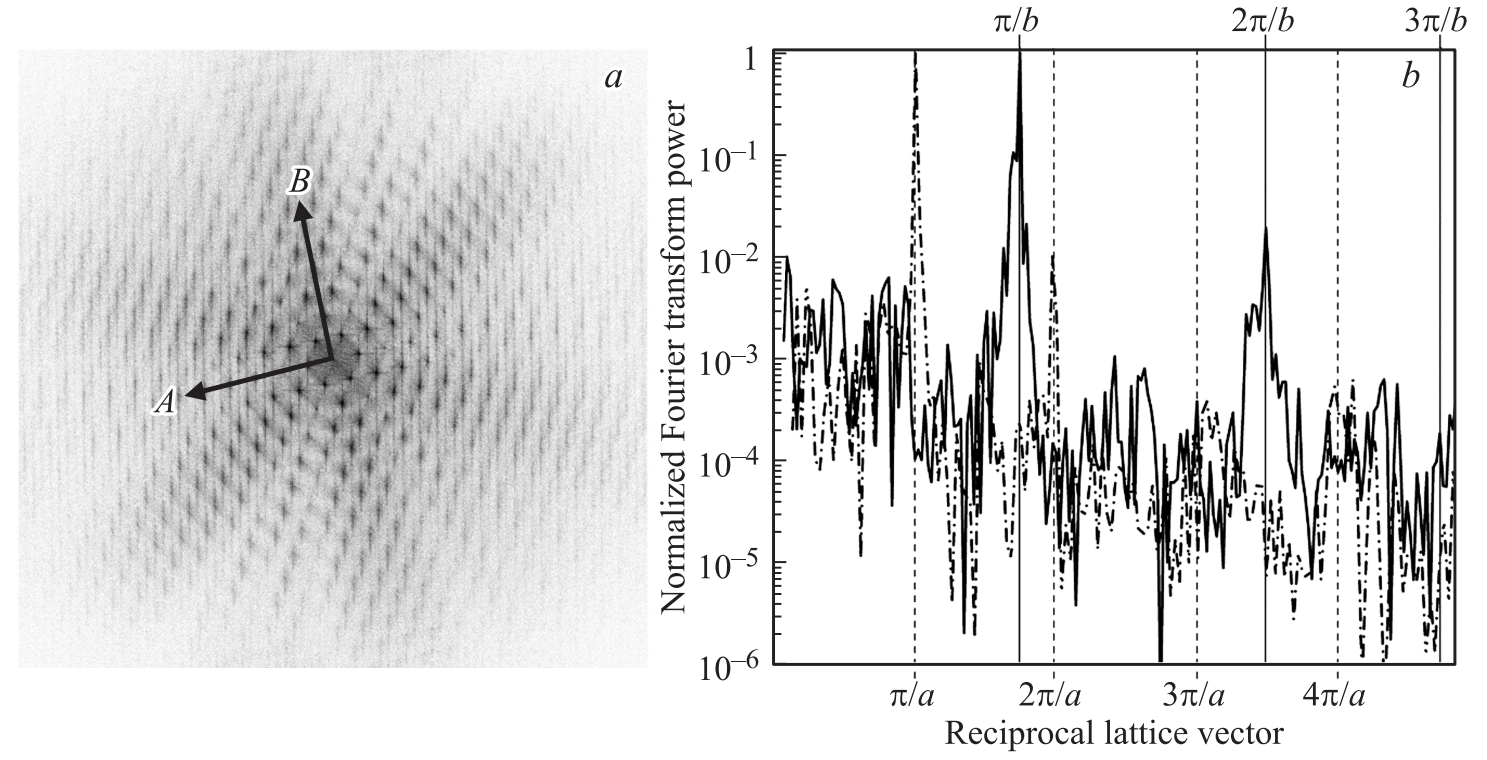

Рис. 3. а) Фурье-образ SEM-снимка (рис. 1), представляющий решетку сфер в обратном пространстве. $A, B-$ два принципиальных направления решетки в обратном пространстве. $b$ ) Распределение яркости в Фурье-образе монослоя сфер (часть $a$ ) вдоль направлений $A$ и $B$ обратной решетки (штрихпунктирная и сплошная линии, соответственно).

роскопии и измерили спектры пропускания и поверхностной дифракции, используя хорошо упорядоченный участок структуры. Полученные данные были соотнесены с расчетом дисперсий дифракционных резонансов в монослое сфер в зависимости от ориентации решетки и поляризации падающего света, а также использованы для демонстрации связи между поверхностной дифракцией и волноводными резонансами в плоском двумерном фотонном кристалле.

\section{2. Образцы и методы измерений}

Образцы были приготовлены путем вылавливания на стеклянную подложку самоорганизованных на поверхности раздела вода-воздух монослоев сфер из полистирола с номинальным диаметром $D=1060 \mathrm{~nm}$, т.е. методом, близким к методу Лэнгмюра-Блоджетт [26]. Размер пленок достигал нескольких квадратных сантиметров.

Электронно-микроскопические снимки приготовленных образцов (рис. 1), полученные в сканирующем электронном микроскопе (SEM), были проанализированы с целью определения диаметра сфер, периода и симметрии их упаковки. Периоды решетки сфер были определены путем анализа двумерных Фурье-образов микроскопических снимков.

Спектры ретроотражения и пропускания были измерены в линейно $s$ - и $p$-поляризованном спектре в диапазоне от 400 до $1700 \mathrm{~nm}$ с помощью спектрометров с фиксированной решеткой QE65000 и NIR512 от Ocean Optics. Схема измерения представлена на рис. 2,c. Освещение образца 4 осуществлялось белым светом от лампы накаливания 1 , который подводился оптическим кабелем диаметром $600 \mu \mathrm{m}$ к фокусирующей и коллимирующей оптике для формирования падающего пучка диаметром $1 \mathrm{~mm}$. Для измерения угловой зависимости спектров в диапазоне от -80 до $80^{\circ}$ была использована вращающаяся с шагом $0.5^{\circ}$ платформа 3. Угловое разрешение с учетом диаметра собирающих отраженный/прошедший свет линз составляло около $1.8^{\circ}$. Часть отраженного света отводилась с помощью полупрозрачной пластинки 2 на спектрометр 6 для измерения ретроотражения. В той же установке измерялись спектры пропускания, если спектрометр располагался в позиции 5. Призменные поляризатор и анализатор были размещены сразу после кабеля осветителя и перед кабелем спектрометра для выделения линейно поляризованной компоненты в световом сигнале.

\section{3. Визуализация решетки монослоя copep}

Фурье-анализ SEM-снимка (рис. 1) позволяет оценить упорядоченность укладки сфер в монослое и определить период решетки. Точность такого анализа ограничена, как правило, неопределенностью в установке плоскости образца по отношению к падающему пучку электронов и, в нашем случае непроводящего образца, искажениями, связанными с зарядкой образца облучающими электронами.

Фурье-образ SEM-снимка монослоя представляет собой обратную решетку гексагонально упакованного монослоя сфер (рис. 3,a), т.е. отображает проекцию решетки параллельных прямых на перпендикулярную им плоскость. Это изображение повернуто на $30^{\circ}$ по отношению к решетке в реальном пространстве на снимке, показанном на рис. 1. Построив профили интенсивности Фурье-образа вдоль двух основных направлений 


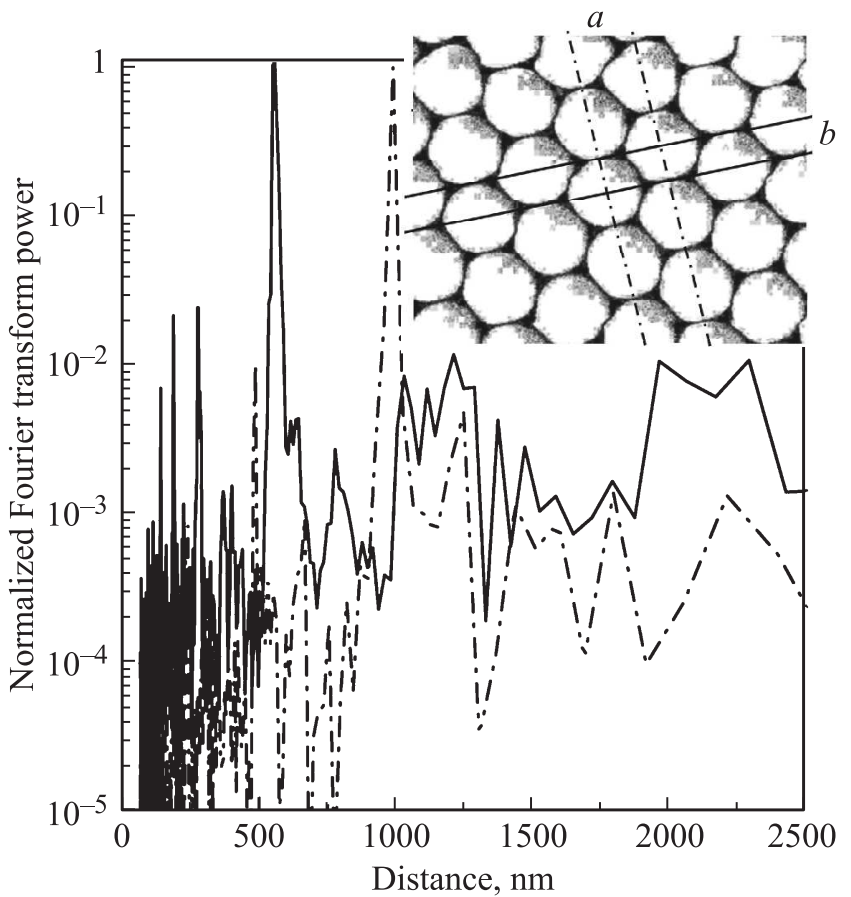

Рис. 4. Два основных периода решетки монослоя, пересчитанные из Фурье-образа (см. рис. 3). Штрихпунктирная и сплошная линии соответствуют постоянным $a$ и $b$ решетки монослоя соответственно. На вставке представлен фрагмент SEM-снимка монослоя с указанием соответствующих периодов решетки.

гексагональной решетки, проходящих через вершины охватывающего центр Фурье-образа наименьшего $(A)$ и следующего по размеру $(B)$ шестиугольников (рис. $3, a)$, можно определить величины векторов обратной решетки $A=2 \pi / a$ и $B=2 \pi / b$, соответствующие радиусам первой и второй координационных окружностей с центом в точке $\Gamma$ (рис. $3, b)$.

Перестроив эти профили в единицах длины, получаем периоды решетки в реальном пространстве $a=960 \mathrm{~nm}$ и $b=554 \mathrm{~nm}$, показанные на рис. 4. Важно отметить, что ни один из полученных периодов не равен диаметру сферы. Построив такие профили для шести азимутальных направлений из точки $\Gamma$, можно увидеть, что решетка изображенного на рис. 1 монослоя сфер несколько искажена. В частности, для первой координационной окружности вершины шестиугольника соответствуют расстояниям от центра 946, 966, 955, 942, 966 и $944 \mathrm{~nm}$.

\section{4. Поверхностная дифракция}

Монослой сфер взаимодействует со светом, как уже упоминалось, подобно плоской двумерной дифракционной решетке. При облучении белым светом исследованных образцов результат наблюдается невооруженным глазом: шесть лучей, расходящихся под углом к направлению распространения падающего пучка света. Такая картина наблюдается для дифракции вперед и назад, т. е. как за образцом, так и перед ним. При нормальном падении пучка белого света на экране позади образца видны несколько порядков дифракции (рис. 5, $a$ и вставка на рис. $5, b$ ). Пятно (удаленное в нашем случае с изображения) вдоль направления падающего пучка это нулевой порядок дифракции. По мере удаления от нулевого порядка следует первый порядок дифракции для периода $a$, названный $A 1$, - шесть ярко окрашенных полосок, расположенных под углами $60^{\circ}$ друг к другу, цвет которых изменяется от синего до красного в направлении от центра (рис. 5, $a$ ). На несколько большем угловом расстоянии от лучей первого порядка наблюдается еще один набор аналогично окрашенных лучей, повернутых на угол $30^{\circ}$ к лучам первого порядка $A 1$ (рис. 5, a), - это также первый порядок дифракции $B 1$, но для решетки с постоянной $b$. Интенсивность и ширина линий $B 1$ много меньше, чем для линий $A 1$. Второй порядок дифракции $A 2$ для периода $a$ выглядит как продолжение лучей первого порядка более тонкими лучами (вставка на рис. 5, $a$ ).

Если падающий пучок освещает сразу несколько поразному ориентированных доменов решетки, дифракционная картина представляет собой суперпозицию нескольких повернутых по азимуту относительно друг друга шестилучевых звездочек (рис. 5,b). При увеличении числа таких доменов лучи заполняют всю окружность, образуя кружок с изменяющимся по радиусу цветом.

Спектры поверхностной дифракции света в зависимости от угла падения пучка на образец были записаны с использованием конфигурации ретроотражения (рис. 2,c). На рис. 6 приведены карты спектров ретроотражения $\left(\mathrm{r} R_{s s}\right)$, измеренные в $s$-поляризованном свете при ориентации плоскости падения вдоль наиболее ярких лучей первого порядка дифракции $A 1$ (рис. $6, a)$ и перпендикулярно им, т. е. вдоль лучей $B 1$ (рис. $6, b)$.

Эти карты показывают несколько дифракционных резонансов различного порядка. При нормальном падении света $\left(\theta=0^{\circ}\right)$ наблюдается нулевой порядок дифракции. Он соответствует стандартному спектру отражения при нормальном падении пучка на монослой. При наклонном падении света наблюдаются резонансы, соответствующие более высоким порядкам дифракции вплоть до максимально возможного при практически касательном падении света на поверхность образца.

Отметим, что в двух использованных азимутальных ориентациях образца представлены различные наборы дифракционных резонансов. Оказалось, что эти резонансы находятся в соответствии с двумя постоянными решетки, найденными с помощью Фурье-анализа SEMснимка (рис. 2), и фотографией дифракционной картины (рис. 5). Угловая дисперсия полос резонансов на рис. 6 удовлетворяет соотношению для дифракции на одномерной решетке полосок

$$
m \lambda=2 d(\sin \theta-\sin (-\theta))=2 d \sin \theta,
$$

где $m$ - порядок дифракции, $d-$ период решетки, $\theta$ - угол падения света относительно нормали к мо- 
$a$

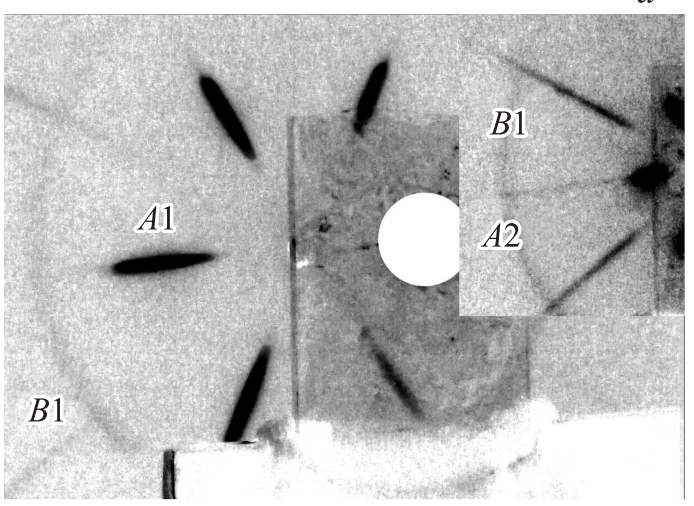

$b$

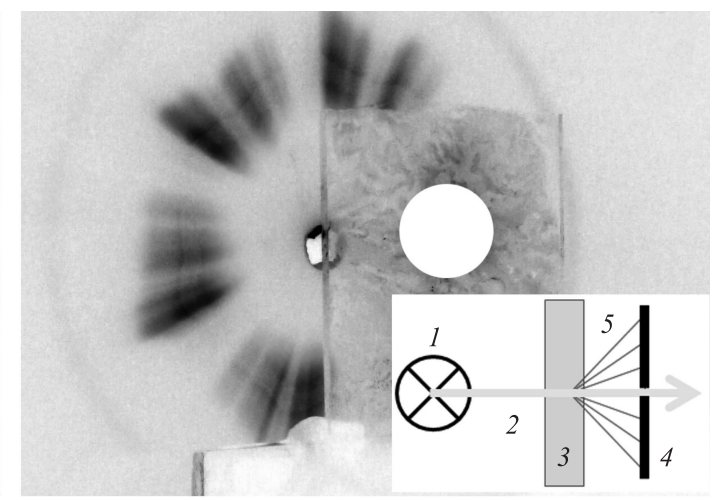

Рис. 5. Визуализация дифракции света, прошедшего через монослой сфер на стеклянной подложке. $A 1, A 2, B 1-$ порядки дифракции для направлений в обратной решетке $A$ и $B$ (см. рис. $3, a$ ). $a$ - фотоснимок дифракции монослоя в случае монокристаллической упаковки сфер в пределах освещенного пятна. На вставке - снимок с увеличенным контрастом (под большим углом наблюдения) для демонстрации более высоких порядков дифракции. $b$ - то же в случае поликристаллической решетки сфер. На вставке показана схема визуализации дифракции: 1 - лампа, 2 - коллимированный луч, 3 - образец, 4 - экран с отверстием для прохода нулевого порядка дифракции, 5 - порядки дифракции.

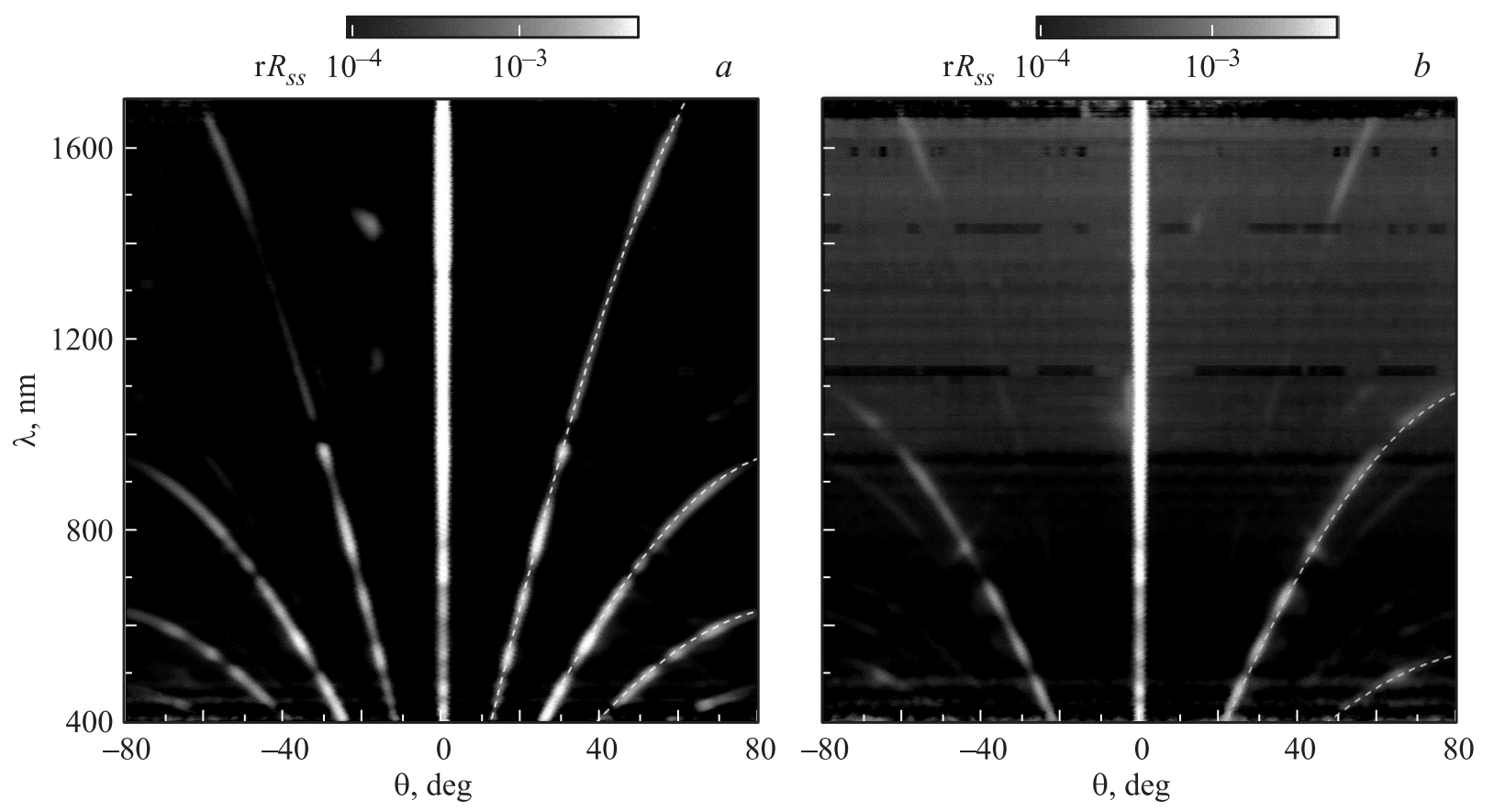

Рис. 6. Карты угловых зависимостей спектров ретроотраженного света, измеренные в $s$-поляризованном свете. $a-$ при ориентации плоскости падения вдоль лепестков $A 1$ порядка дифракции (рис. 5, $a$ ), рис. 5, $b-$ вдоль $B 1$ (b) порядка дифракции (между лепестками $A 1$ порядка дифракции). Штриховые линии показывают дисперсии поверхностной дифракции, рассчитанные по формуле (1) для постоянных одномерной решетки с периодами $a(a)$ и $b(b)$. Над картами показана шкала интенсивности.

нослою сфер. Это стандартное выражение для поверхностной дифракции, записанное с учетом углов падения/детектирования при измерении ретроотражения.

При ориентации плоскости падения в плоскости $A$-дифракции присутствуют порядки дифракции с индексами $m=1,2,3,4$. Карта, полученная при ориентации плоскости падения перпендикулярно направлению $A$-дифракции, демонстрирует два доминирующих по яркости порядка $m=1,2$ резонансов $B$-дифракции.
Для аппроксимации дисперсий этих резонансов периоды были определены по Фурье-образу SEM-снимка образца (рис. 4). Следует отметить, что поверхностная дифракция не дает периода, равного диаметру сферы, а определена параметрами решетки $a \approx \sqrt{3} D / 2$ и $b \approx 0.5 D$ (вставка на рис. 4). Отметим, что о дифракции с периодом $b$ ранее не сообщалось $[23,24]$.

В случае $B$-ориентации плоскости падения нам не удалось полностью избежать вклада от $A$-направления, 

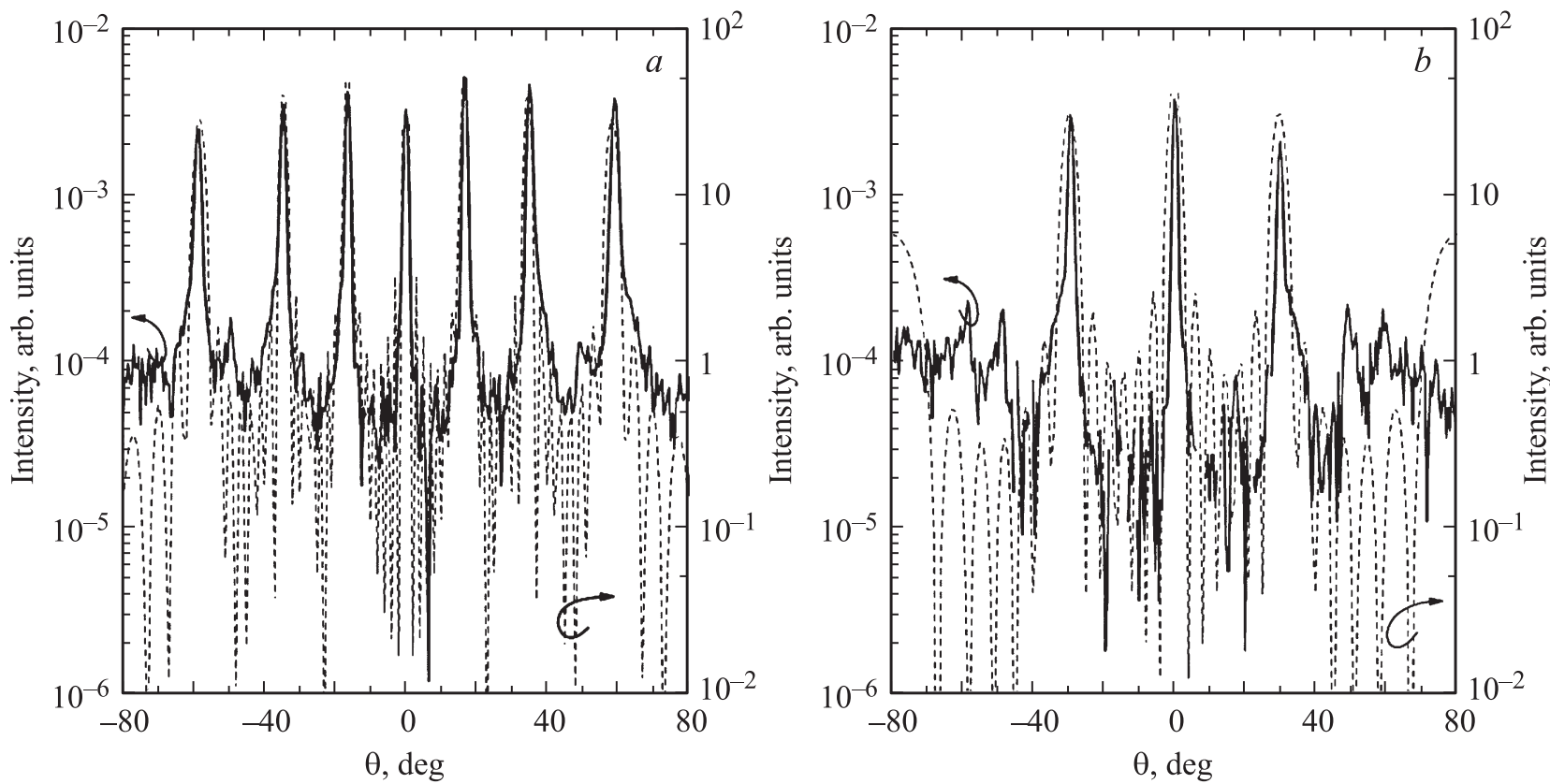

Рис. 7. Угловые зависимости интенсивности дифрагированного света, измеренные для длины волны $\lambda=550 \mathrm{~nm}$ при ориентации плоскости падения вдоль $(a)$ и поперек $(b)$ плоскости дифракции $A 1$. Пунктирные линии показывают угловые распределения интенсивности дифрагированного света на двух одномерных решетках, рассчитанные по формуле (2).

что, возможно, объясняется неточностью азимутальной юстировки образца, апертурой собирающей свет оптики, а также искажением решетки сфер монослоя относительно гексагональной симметрии. Тем не менее в первом приближении можно утверждать, что путем азимутальной ориентации плоскости падения света можно разделить поверхностную дифракцию на гексагонально упорядоченном монослое сфер на вклады от шести $A$ и шести $B$ одномерных решеток.

Для описания интенсивности углового распределения поверхностной дифракции применима формула Фраунгофера для распределения интенсивности дифрагированного света при нормальном падении луча [27]

$$
J_{\varphi}=J_{0} \frac{\sin ^{2} u}{u^{2}} \frac{\sin ^{2} N v}{\sin ^{2} v},
$$

где $u=\pi t \sin \varphi / \lambda, v=\pi d \sin \varphi / \lambda, J_{0}-$ интенсивность колебания, определяемая одной щелью в направлении вдоль пучка, $N-$ число щелей, $\varphi-$ угол дифракции, $t$ - ширина щели, $d-$ период решетки. Второй сомножитель описывает дифракцию на одной щели, а третий - интерференцию $N$ дифрагированных лучей.

На рис. 7, $a$ представлена аппроксимация экспериментальной угловой зависимости интенсивности дифракции на длине волны $\lambda=550 \mathrm{~nm}$ для спектра, показанного на рис. 6, $a$ (период $a$ ), а на рис. 7, $a$ - для спектра на рис. $6, b$ (период $b$ ). Наиболее значительные изменения расчетной кривой происходят при изменении числа дифрагирующих элементов. Следует отметить, что формальные условия применимости формулы (2) не вполне соблюдены, так как мы пренебрегли коррекцией амплитудного фактора, хотя в случае сфер размер отражающей поверхности каждого элемента решетки сравним с длиной волны или меньше ее.

Наилучшее соответствие эксперименту по относительной величине интенсивности и ширине резонансов достигается при использовании $N=8$ для рис. 7, $a$ и $N=7$ для рис. 7, $b$. Таким образом, участок решетки, ответственный за формирование дифракционной картины, ограничен областью в десяток сфер микронного диаметра, как показано штриховой окружностью на рис. 1. Размер области согласуется с длиной когерентности излучения лампы накаливания, составляющей около $10 \mu \mathrm{m}$ в видимой области спектра. Столь малая площадь образца (примерно в $\sim 100 \mu \mathrm{m}^{2}$ ), необходимая для формирования поверхностной дифракции, согласуется с наблюдением яркого цветного круга в случае поликристаллической решетки, попадающей в поле освещенного пятна диаметром $1 \mathrm{~mm}$. Кроме того, эта характерная величина объясняет дифракционное окрашивание слабоупорядоченных монослоев сфер.

\section{5. Дифракция света в монослое сфер}

Интерференция многократно рассеянного света, локализованного в объеме монослоя, приводит к формированию блоховских мод, соответствующих симметрии решетки и способных распространяться в периодическом профиле показателя преломления монослоя. Зонная структура предполагает дифракцию света на границах зоны Бриллюэна. На рис. 8, a граница первой зоны Бриллюэна представлена шестиугольником (сплошная толстая линия) на фоне фрагмента обратной решетки 


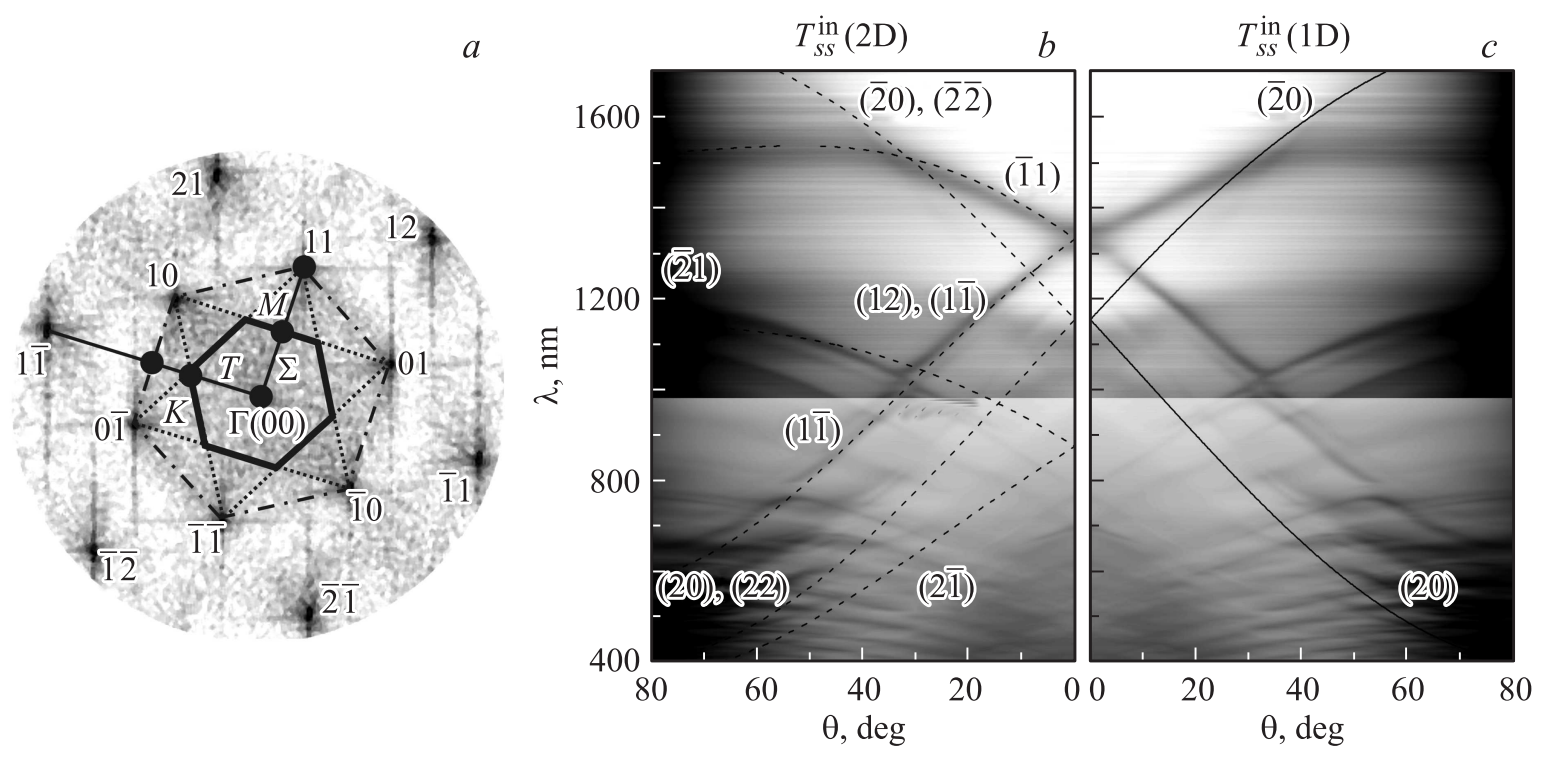

Рис. 8. $a-$ - фрагмент Фурье-образа решетки монослоя (рис. 3, a) вблизи точки Г(00). Цифрами обозначены узлы гексагональной решетки в обратном пространстве. Сплошной толстой линией показана граница первой зоны Бриллюэна, штриховой - второй зоны, штрихпунктирной - третьей. ГM и ГK - характерные направления в обратной гексагональной решетке. $\Sigma$ и $T-$ длины отрезков ГM и ГK. $b, c$ - одинаковые карты угловых зависимостей спектров пропускания $T_{s s}^{\text {in }}$, измеренные при ориентации плоскости падения $s$-поляризованного света вдоль направления ГМ. На эти карты наложены рассчитанные по формуле (3) дисперсии дифракционных резонансов в „пустой“ гексагональной решетке для периода, отвечающего расстоянию $\Sigma$ в первой зоне Бриллюэна. Линии на частях $b$ и $c$ представляют дисперсии резонансов двумерных (2D) и одномерных (1D) решеток соответственно. Цифрами обозначены резонансы с участием показанных на части $a$ векторов обратной решетки.

образца с центром в точке Г. Этот шестиугольник повернут на $30^{\circ}$ относительно узлов обратной решетки, т.е. он совпадает по азимутальной ориентации с расположением узлов решетки в реальном пространстве. Далее будем использовать общепринятые обозначения для зонной структуры гексагональной решетки. Характерные размеры зоны - отрезки ГM (направление $A$ ) и $\Gamma K$ (направление $B$ ), длинам которых $\Sigma$ и $T$ по построению отвечают расстояния $2 a$ и $3 b$ в решетке сфер в реальном пространстве.

На рис. 8, $b$ представлена карта пропускания, измеренная в $s$-поляризованном свете при ориентации плоскости падения вдоль $A$-направления поверхностной дифракции (аналогично рис. $6, a$ ). Мы наложили на эту карту дисперсии невзаимодействующих волноводных резонансов, рассчитанные для „пустой“ двумерной гексагональной решетки (решетка без контраста показателя преломления) с постоянной $d=2 a=1920 \mathrm{~nm}$, используя выражение

$$
\begin{aligned}
k(\omega)= & \pm \sqrt{k_{\mathrm{GR}}(\omega)^{2}-\left(\frac{2 \pi}{d \sqrt{3}}(2 j-i)\right)^{2}} \\
& -\frac{2 \pi i}{d}, \quad i, j=0, \pm 1, \pm 2, \ldots,
\end{aligned}
$$

где $k_{\mathrm{GR}}(\omega)=\frac{2 \pi}{\lambda} n_{\mathrm{PS} \mathrm{ML}} \quad-$ волновой $\quad$ вектор $\quad$ волноводного резонанса (GR) в плоскости решетки, $k=\frac{2 \pi}{\lambda} \sin \theta-$ волновой вектор падающего света, $n_{\mathrm{PSML}}^{2}=f n_{\mathrm{PS}}^{2}+(1-f) n_{\mathrm{air}}^{2}-$ эффективный показатель преломления монослоя сфер из полистирола (PS), $f=\pi / 3 \sqrt{3}-$ объемная доля сфер в монослое, $i, j-$ индексы узлов решетки. Отметим, что на рис. $8, b$ показана только выборка из нескольких дисперсий, которым отвечают наблюдаемые резонансы. Зачастую эти резонансы дважды вырождены в силу симметрии решетки.

Следует отметить, что некоторые моды, такие как (11) для периода $1920 \mathrm{~nm}$, пересекаются при $\theta=0^{\circ}$ в районе $2500 \mathrm{~nm}$, сходясь к полуволновому резонансу ФабриПеро на толщине монослоя. Однако эта спектральная область находится за пределами спектрального диапазона использованных приборов. Следует ожидать, что добротность этого резонанса должна быть весьма мала из-за модуляции поверхностей монослоя.

Для поверхностной дифракции, измеренной в $A$ - и $B$-направлениях, одномерная дифракция оказалась приемлемым способом описания. Положив в формуле (3) индекс $j=0$, можно проверить, справедлива ли одномерная модель в случае дифракции в плоскости монослоя. Из рис. 8,c очевидно, что одномерной решетки недостаточно для описания наблюдаемых резонансов, т.е. падающий свет возбуждает всю совокупность волноводных резонансов в двумерной решетке в согласии с представлением о многократном рассеянии света в монослое.

Тем не менее спектры пропускания демонстрируют азимутальную анизотропию. Спектры пропускания, представленные на рис. 9, были измерены при тех же ориентациях плоскости падения, что и спектры поверх- 

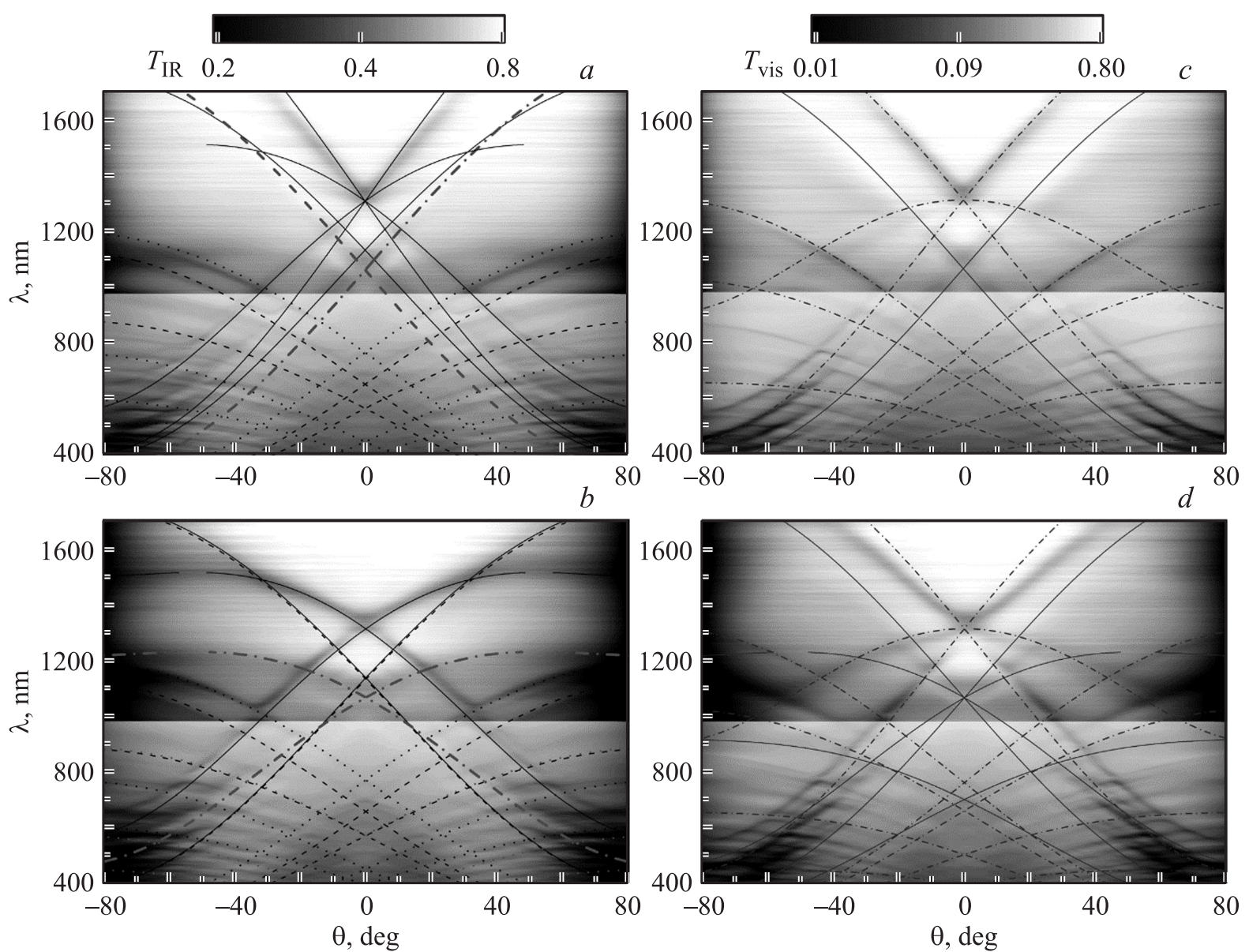

Рис. 9. Карты угловых зависимостей спектров пропускания, измеренные при ориентации плоскости падения света вдоль направления ГM $(a, b)$ и вдоль направления ГK $(c, d)$ при р-поляризации падающего и прошедшего света $(a, c)$ и $s$-поляризации света $(b, d)$. На эти карты наложены рассчитанные по формуле (3) дисперсии дифракционных резонансов в „пустой“ гексагональной решетке: $a, b$ - для периодов $1920 \mathrm{~nm}$ (сплошная линия), $960 \mathrm{~nm}$ (штриховая линия) и $640 \mathrm{~nm}$ (пунктир), $c, d-$ для периодов $1662 \mathrm{~nm}$ (сплошная линия), $1108 \mathrm{~nm}$ (штрихпунктир). Толстыми штрихпунктирными линиями на частях $a, b$ показаны дисперсии с частей $c$ и $d$. Шкалы интенсивности для частей $a-d$ одинаковы, но различны для спектров в видимом (vis) и инфракрасном (IR) диапазонах.

ностной дифракции, раздельно для $s$ - и $p$-поляризованного света. Как видно, профиль резонансов у всех карт индивидуален. Это наблюдение совпадает с общими представлениями о зонной фотонной структуре плоских двумерных фотонных кристаллов [28].

Сплошные линии на картах пропускания на рис. 9, $a, b$, измеренных вдоль направления ГМ, - это дисперсии волноводных резонансов в решетке с периодом $d=1920 \mathrm{~nm} \approx 2 a$, а на картах на рис. 9, $c, d$, измеренных вдоль направления $\Gamma K$, - в решетке с периодом $d=1662 \mathrm{~nm} \approx 3 b$. На этих картах выбраны резонансы только с такими сочетаниями индексов $(i, j)$ из формулы (3), которым отвечают экспериментально наблюдаемые резонансы. Эти дисперсии достаточно близко описывают минимумы пропускания в длинноволновой части спектра, но их, очевидно, недостаточно для описания всех наблюдаемых минимумов.

Следующий резонанс в направлении ГМ должен соответствовать узлу (11) обратной решетки, в котором сходятся вершины второй и третьей зон Бриллюэна (рис. 8,a). Соответствующий период решетки сфер $d=a \approx 960 \mathrm{~nm}$. В направлении ГK следующий резонанс отвечает границе третьей зоны Бриллюэна с периодом $d \approx 2 a \approx 1108 \mathrm{~nm}$. Соответствующие дисперсии волноводных резонансов показаны на картах пропускания штриховыми и штрихпунктирными линиями. Дополнительно мы добавили третий порядок дифракции в направлении ГМ с периодом $d=2 a / 3 \approx 640 \mathrm{~nm}$, чтобы показать, что коротковолновые минимумы пропускания могут быть аппроксимированы путем учета дифракции у границ следующих зон Бриллюэна.

Интересно отметить, что часть особенностей спектров пропускания в направлении ГM может быть учтена только с привлечением дифракции в направлении ГК. Эти особенности показаны на картах пропускания для ориентации ГM (рис. 9, $a, b)$ толстыми штрихпунктирными линиями. Характерно, что заимствованные резонансы различны для ортогональных поляризаций света. Предположительно возбуждение нехарактерных для данной ориентации плоскости падения резонансов явля- 

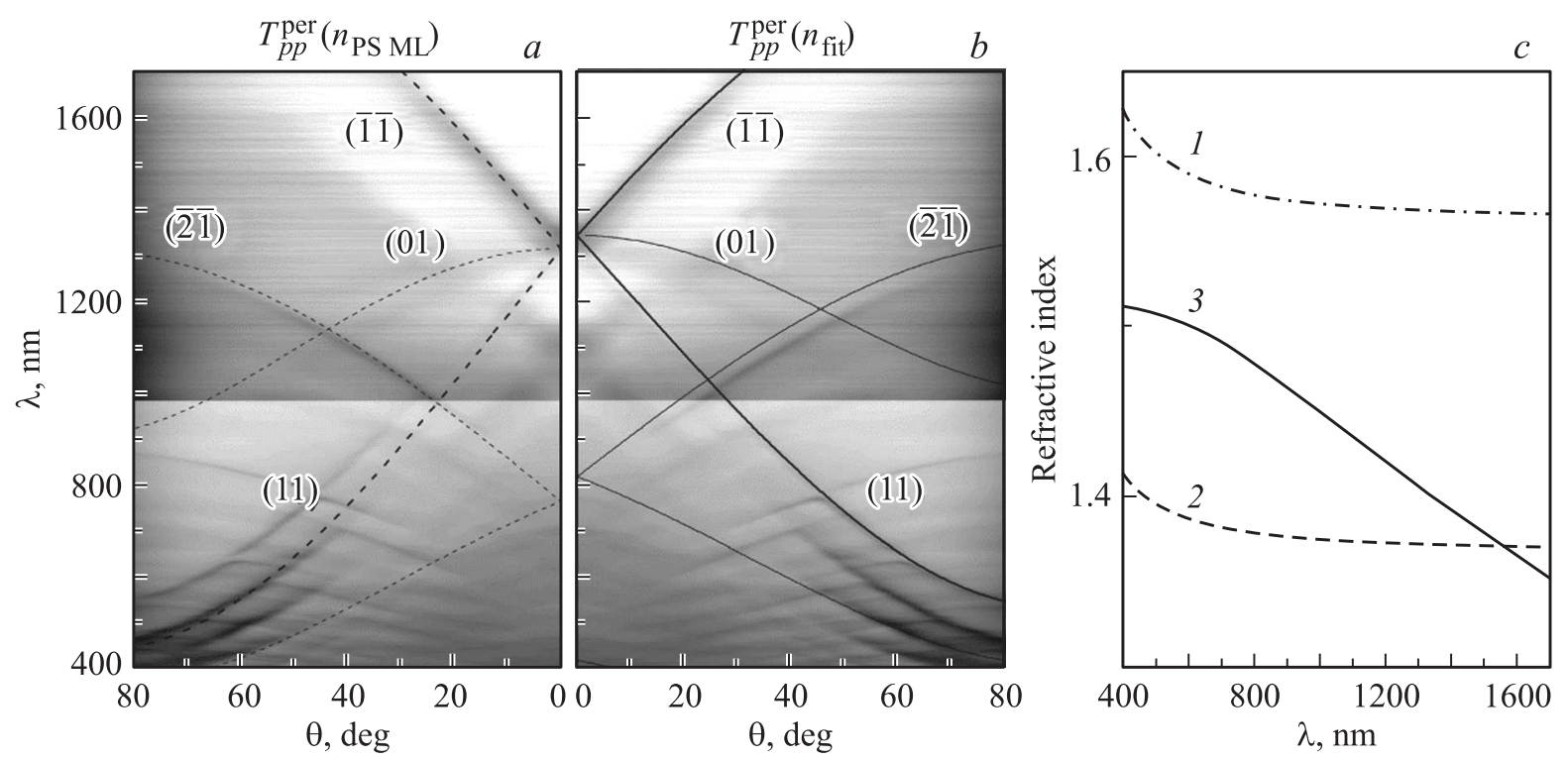

Рис. 10. $a, b$ - одинаковые карты угловых зависимостей спектров пропускания, измеренные в $p$-поляризованном свете при ориентации плоскости падения поперек плоскости $A 1$ порядка дифракции, т. е. в направлении ГK $\left(T_{p p}^{\text {per }}\right)$. Дисперсии дифракционных резонансов в „пустой“ решетке, показанные на части $a$, рассчитаны для эффективного показателя преломления монослоя плотноупакованных сфер полистирола $n_{\mathrm{PSML}}$. Дисперсии, показанные на части $b$, рассчитаны для показателя преломления $n_{\mathrm{fit}}$, позволяющего аппроксимировать экспериментальную дисперсию дифракционного резонанса (11). $c$ - табличная дисперсия показателя преломления полистирола (1), а также дисперсии $n_{\mathrm{PSML}}(2)$ и $n_{\mathrm{fit}}(3)$.

ется следствием многократного рассеяния и искажений решетки.

Несложно заметить, что расчетные дисперсии волноводных резонансов „пустой“ воспроизводят минимумы пропускания на измеренных картах. При этом величина отклонения различна для разных резонансов. Это известное явление в случае плоских двумерных фотонных кристаллов. Причина его состоит в несовпадении распределения электромагнитного поля моды с геометрическим сечением решетки, т. е. каждая мода имеет свой эффективный показатель преломления. Более того, при изменении длины волны локализация поля моды в сечении сферы изменяется. Ситуацию можно поправить, если ввести в расчет частотно-зависимый показатель преломления [19], в нашем случае в формулу (3).

Возьмем, например, дисперсию резонанса (11) в направлении ГK, который наблюдается практически во всем спектральном диапазоне (рис. 10,a). В красной части спектра расчетная дисперсия отстает от экспериментальной, а в голубой - опережает. Это разумно, так как при больших длинах волн поле моды ,провисает за пределы сфер монослоя, а при малых, когда $D>\lambda$, перекрытие поля и сфер улучшается [29]. При этом изменяется эффективный показатель преломления среды для данного резонанса, который и определяет дисперсию в случае „пустой“ решетки. В целом, по нашему мнению, моделирование распределения поля в резонансе в зависимости от угла падения света для всех длин волн - задача, трудоемкая и не имеющая практического значения.
Мы решили обратную задачу, заложив эмпирическую дисперсию резонанса в уравнение (3) и решив его относительно показателя преломления. Результаты показаны на рис. $10, b, c$. Как видно из рис. $10, c$, показатель преломления резонанса (11) (кривая 3) несколько ниже эффективного показателя преломления монослоя (кривая 2) в длинноволновом пределе, с уменьшением длины волны он монотонно возрастает, хотя и остается меньше показателя преломления массивного полистирола [30]. Применив скорректированный показатель преломления к другим резонансам, мы получили дисперсии, которые аппроксимируют экспериментальную кривую также не лучшим образом, а в случае резонанса $(\overline{2} \overline{1})$ соответствие даже ухудшилось. Такое поведение согласуется с представлением о собственных индексах волноводных резонансов, зависящих от степени перекрытия поля с каркасом фотонного кристалла.

\section{6. Взаимосвязь поверхностной дифракции и волноводных резонансов}

Наиболее интригующей задачей является поиск взаимосвязи между двумя дифракционными явлениями, происходящими в одной и той же структуре. Общепринято, что собственные моды фотонного кристалла существуют только в объеме этого кристалла, а при выходе поля за пределы кристалла в ближней волновой зоне происходит связывание этих мод с модами свободного пространства. При этом мы исключаем из рассмотрения аномалию Рэлея, т. е. случай порядка дифракции, имеющего волновой 


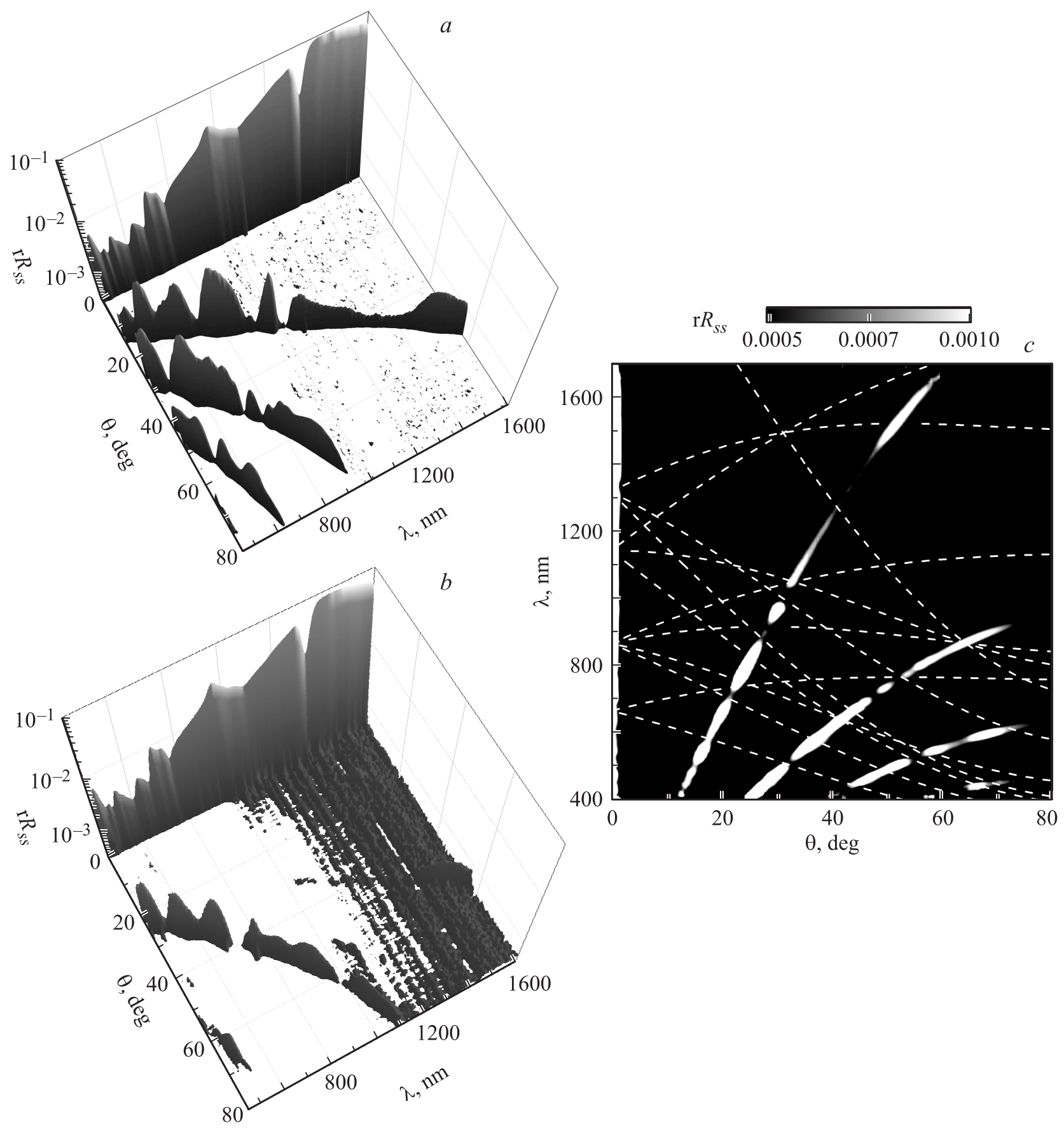

Рис. 11. Трехмерные графики ретроотражения, измеренные в $s$-поляризованном свете при ориентации плоскости падения вдоль направлений $\Gamma M(a)$ и $\Gamma K(b) . c$ - карта угловой зависимости ретроотраженного света в $s$-поляризованном свете при ориентации плоскости падения вдоль направления ГМ. Штриховые линии показывают дисперсии волноводных резонансов „пустой“ решетки для периода $1920 \mathrm{~nm}$.

вектор вдоль поверхности [31], поскольку не очевидны как ее локализация на поверхности структуры с малым контрастом показателя преломления, так и ее отличие от собственной моды фотонного кристалла.

Из опыта исследований оптических свойств трехмерных фотонных кристаллов следует, что в свободном пространстве наблюдаются явления, связанные с дифракцией света внутри структуры, например полоса отражения в области резонанса брэгговского зеркала. Из опыта исследований оптических свойств фотонных кристаллов также известно, что в дальнем поле наблюдается модуляция спектра нулевого порядка дифракции за счет собственных мод фотонного кристалла, например брэгговский резонанс в стандартных спектрах отражения. Для более высоких порядков дифракции о подобных наблюдениях не сообщалось. 
Если построить на одном графике порядки поверхностной дифракции в логарифмическом масштабе, то видно, что их интенсивность существенно изменяется с длиной волны (рис. 11,a). Более того, интенсивности ненулевых порядков дифракции изменяются в резонансах многократно, до 10 раз, превосходя относительную величину модуляции спектра отражения резонансами в нулевом порядке. Причем если модуляция интенсивности дифрагированного света в нулевом порядке не зависит ни от азимутальной ориентации решетки, ни от поляризации падающего света, то это вырождение очевидным образом снимается при наклонном падении света на решетку (ср. рис. 11, $a$ и $b$ ).

Наблюдаемая модуляция интенсивности различных порядков поверхностной дифракции связана с волноводными резонансами монослоя сфер как фотонного кристалла. Этот эффект проявляется при наложении расчетных дисперсий волноводных резонансов (направление ГM) на соответствующую карту поверхностной дифракции (рис. 11,c). Хотя однозначной корреляции из этого рисунка не следует, очевидно, что минимумы интенсивности поверхностной дифракции наблюдаются там, где есть волноводные резонансы. Тот факт, что не для всех волноводных резонансов происходит такое взаимодействие, может быть приписан различной симметрии поля этих резонансов.

Если рассмотреть модуляцию как обмен энергией между волноводными резонансами в фотонном кристалле и дифракционными явлениями в свободном пространстве, то можно заключить, что энергия электромагнитного поля, запасенная в этих процессах, имеет приблизительно одинаковое значение. А поскольку интенсивность поверхностной дифракции измеряется непосредственно в ретроотражении, можно оценить интенсивность света, связанного с волноводными резонансами фотонного кристалла. Такая оценка полезна для образцов, в которых измерение спектров пропускания невозможно по конструктивным причинам. Величина потока, захваченного фотонным кристаллом, является важным параметром для их практических приложений в устройствах управления потоком излучения, интегрированных с солнечными батареями и излучателями света.

Наконец, рассмотрим карты пропускания, измеренные в $s$-поляризованном свете в ориентациях ГM и ГK плоскости падения света, но представленные в координатах приведенная частота-волновой вектор $(D / \lambda-2 \pi / \lambda)$, с добавлением дисперсий поверхностных резонансов (рис. 12). Дисперсии поверхностных резонансов становятся вертикальными линиями и сразу же бросается в глаза тот факт, что их пересечение с волноводными резонансами фотонного кристалла сопровождается антипересечениями последних, что характерно для границ зоны Бриллюэна. Таким образом, особые точки зон Бриллюэна совпадают с условиями поверхностной дифракции. А значит, спектры на рис. $11, a, b-$ это спектры поверхностной дифракции фотонного кристалла, привязанные к особым точкам его зон Бриллюэна.

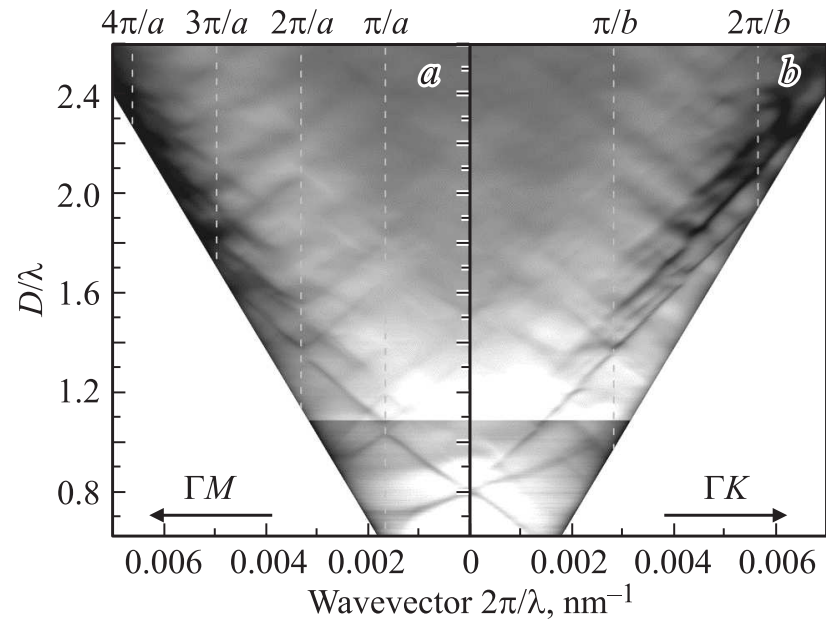

Рис. 12. Карты угловых зависимостей спектров пропускания, измеренные при ориентации плоскости падения света вдоль направлений $\Gamma M(a)$ и ГK $(b)$ при $s$-поляризации падающего и прошедшего света. На эти карты наложены дисперсии поверхностных дифракционных резонансов (штриховые линии) при соответствующих ориентациях монослоя относительно плоскости падения света.

Поскольку антипересечение дисперсий вызвано многоволновой дифракцией [32], с теоретической точки зрения было бы интересно изучить вопрос об участии поверхностно-дифрагированной волны в этом процессе.

И последнее замечание. В расширенной зонной структуре (рис. 12) границы спектра близки к световой линии для монослоя. При этом контраст волноводных резонансов оказывается выше вблизи этой линии, уменьшаясь к центру зоны Бриллюэна. Связано такое изменение с потерями волноводных резонансов на излучение в свободное пространство. При этом спектры, измеренные вблизи световой линии, должны нести информацию о перестройке волноводных мод (собственных мод фотонного кристалла вне светового конуса) в волноводные резонансы фотонного кристалла (излучающие собственные моды в пределах светового конуса) (см. рис. 3 в [13]).

\section{7. Заключение}

Мы представили систематическое исследование дифракционных явлений в упорядоченном монослое монодисперсных сфер, связав структуру образца с двумя возможными сценариями его взаимодействия с падающим светом. Благодаря сравнительно хорошей структуре исследованных образцов и применению оригинальной методики ретроотражения совместно со спектроскопией пропускания нам удалось выявить анизотропию дифракционных явлений, связанную с азимутальной ориентацией плоскости падения света и поляризацией падающего света.

Большое количество наблюдаемых оптических резонансов поставило задачу их классификации и соотне- 
сения с параметрами решетки сфер в монослое. Эта задача, решенная в частном случае монослоя сфер, имеет общее значение для понимания функциональности фотонных кристаллов. Во-первых, достаточно простая структура монослоя позволила идентифицировать периоды структуры, ответственные за различные резонансы. Во-вторых, мы наглядно продемонстрировали подавление фраунгоферовской дифракции света на решетке фотонного кристалла в случае пересечения дисперсий этой дифракции с дисперсиями собственных волноводных резонансов в объеме фотонного кристалла. В-третьих, мы показали, что порядки поверхностной дифракции соответствуют дифракции в особых точках на границах зон Бриллюэна плоского двумерного фотонного кристалла.

Ряд вопросов остался открытым и требует теоретического осмысления: например, правила отбора для волноводных резонансов, проявление волноводных резонансов в спектрах ретроотражения, механизм многоволновой дифракции в областях антипересечения дисперсий волноводных резонансов и дисперсий поверхностной дифракции и некоторые другие.

Следует отметить, что описанный подход к дифракции света в монослоях коллоидных сфер может быть распространен на другие плоские двумерные фотонные кристаллы независимо от симметрии, структуры и состава их каркаса.

Автор признателен N. Vogel за предоставление замечательных образцов, C.K. Weiss за SEM-снимки образцов и О. Zhuromskyу за плодотворные дискуссии.

\section{Список литературы}

[1] M. Inoue. Phys. Rev. B 36, 2852 (1987).

[2] K. Ohtaka, H. Miyazaki, T. Ueta. Mater. Sci. Eng. B 48, 153 (1997).

[3] Y. Kurokawa, H. Miyazaki, Y. Jimba. Phys. Rev. B 69, 155117 (2004).

[4] X. Ye, L. Qi. Nano Today 6, 608 (2011).

[5] H. Zheng, S. Ravaine. Crystals 6, 54 (2016).

[6] S.G. Romanov, S. Orlov, D. Ploss, C.K. Weiss, N. Vogel, U. Peschel. Sci. Rep. 6, 27264 (2016).

[7] N. Vogel, S. Goerres, K. Landfester, C.K. Weiss. Macromol. Chem. Phys. 212, 1719 (2011).

[8] N. Vogel, L. de Viguerie, U. Jonas, C.K. Weiss, K. Landfester. Adv. Funct. Mater. 21, 3064 (2011).

[9] N. Vogel, M. Retsch, C.A. Fustin, A. del Campo, U. Jonas, Chem. Rev. 115, 6265 (2015).

[10] S.G. Romanov, A. Regensburger, A.V. Korovin, U. Peschel. Adv. Mater. 23, 2515 (2011).

[11] L. Shi, X. Liu, H. Yina, J. Zi. Phys. Lett. A 374, 1059 (2010).

[12] X. Yu, L. Shi, D. Han, J. Zi, P.V. Braun. Adv. Funct. Mater. 20, 1910 (2010).

[13] S.G. Romanov, S. Orlov, A.V. Korovin, G.P. Chuiko, A. Regensburger, A.S. Romanova, A. Kriesch, U. Peschel. Phys. Rev. B 86, 195145 (2012).

[14] P. Zhan, Z. Wang, H. Dong, J. Sun, J. Wu, H.-T. Wang, S. Zhu, N. Ming, J. Zi. Adv. Mater. 18, 1612 (2006).

[15] L. Landstrom, D. Brodoceanu, D. Bauerle, F.J. Garcia-Vidal, S.G. Rodrigo, L. Martin-Moreno. Opt. Exp. 17, 761 (2009).
[16] R.M. Cole, Y. Sugawara, J.J. Baumberg, S. Mahajan, M. Abdelsalam, P.N. Bartlett. Phys. Rev. Lett. 97, 137401 (2006).

[17] Y. Lan, S. Wang, X. Yin, Y. Liang, H. Dong, N. Gao, J. Li, H. Wang, G. Li. Nanoscale 8, 13454 (2016).

[18] I. Zharov, A. Khabibullin. Acc. Chem. Res. 47, 440 (2014).

[19] S. Fan, J.D. Joannopoulos. Phys. Rev. B 65, 235112 (2002).

[20] A. David, H. Benisty, C. Weisbuch. Rep. Prog. Phys. 75, 12650 (2012).

[21] С.Г. Романов. ФТТ 49, 512 (2007).

[22] J. Küchenmeister, C. Wolff, K. Busch, U. Peschel, S.G. Romanov. Adv. Opt. Mater. 1, 952 (2013).

[23] B. van Duffel, R.H.A. Ras, F.C. De Schryver, R. A. Schoonheydt. J. Mater. Chem. 11, 3333 (2001).

[24] S.G. Romanov, M. Bardosova, I. Povey, M. Pemble, C.M. Sotomayor Torres. Appl. Phys. Lett. 92, 191106 (2008).

[25] S.G. Romanov. Photonic crystal materials and devices XII / Eds D. Gerace. G. Lozano, C. Monat, S.G. Romanov. Proc. SPIE 9885, 98850V (2016).

[26] M. Bardosova, M.E. Pemble, I.M. Povey, R.H. Tredgold. Adv. Mater. 22, 3104 (2010).

[27] Г.С. Ландсберг. Оптика. 6-е изд. Физматлит, М. (2003). $848 \mathrm{c}$.

[28] J.D. Joannopoulos, S.G. Johnson, J.N. Winn, R.D. Meade. Photonic crystals: molding the flow of light. 2nd ed. Princeton University Press (2008). 304 p.

[29] M. López-García, J.F. Galisteo-López, C. López, A. GarcíaMartín. Phys. Rev. B 85, 235145 (2012).

[30] N. Sultanova, S. Kasarova, I. Nikolov. Acta Phys. Pol. A 116, 585 (2009).

[31] L. Rayleigh. Proc. Roy. Soc. A 79, 399 (1907).

[32] В.А. Кособукин. ФТТ 47, 1954 (2005). 